necessary, to consider the desirability of releasing members of the profession from their undertakings and pledges in connexion with the National Insurance Act, and further, to consider the situation created by the attitude of the Government towards the decisions of the Representative Body.

By the new regulations issued by the Local Government Board on Dec. 20th, 1912, non-pulmonary tuberculosis is to be included from Feb. 1st, 1913, in the list of compulsorily notifiable diseases. This step appears to be in view of the fact that half the deaths from these forms of complaint occur in children under five years of age, and it is hoped thereby to effect an improvement in the environment of such children.

\section{THE IDEAL LESION PRODUCED BY JUDICIAL HANGING.}

By Frederic WoOd-Jones, D.SC., M.B., B.S. LoNd., DIRECTOR OF THE DEPARTMENT OF ANATOMY, 'IHE LONDON SCHOOL OF MEDICINE FOR WOMEN.

THERE are at present in the Museum of the Royal College of Surgeons of England two most interesting series of examples of the lesion caused by judicial hanging : the first series is seen among the Roman period skulls of the Nubian Survey collection, and the second is a recent donation from Captain C. F. Fraser, I.M.S., one time superintendent of Rangoon Central Jail.

The first series has already been discussed in various publications, and may be summarised brielly as skulls showing a peculiar fracture of the base (depicted in Fig. 1)

FIG. 1.

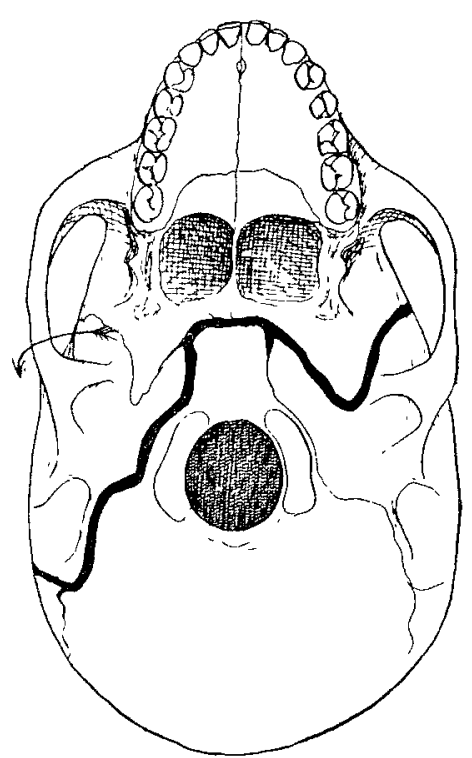

The lesion present in the Nubian series of hangings and in the skull of Dr. Pritchard. Fractured base of the skull; effect of a subaural knot.

following upon leverage imparted to one temporal bone by a knot placed beneath the angle of the jaw. The position of the knot was a matter of conjecture in these Nubian skulls, yet the causation of the lesion appeared to be so clear that it seemed possible to say in any given skull upon which side of the head the knot was placed.

In 1865 Pritchard was executed for his crimes, and in February, 1912, his skull was described by Dr. G. H. Edington. From the lesion shown in this skull (a lesion identical with that in the Nubian series) one felt justified in further discussion in stating as an assumption that the knot had been placed far back upon the jaw, as it clearly seemed to have been in the Nubian series. It also seemed to be a just assumption that the knot in Pritchard's case was placed upon the right side. It has recently come to my knowledge that a medical man who actually witnessed the execution can corroborate this assumption. He noted the position of the knot, and standing to the right of the scaffold he "distinctly remembers that the criminal's head lay over towards the left shoulder" after the drop.

Such a knot is termed subaural, and for some reasonprobably because there is little fear of it slipping-it is the favourite with hangmen; and yet from its very frequent failure to produce any lesion of the neck and to cause instantaneous death it can only be described as a very bad one. Death by fracture of the base of the skull, or, falling short of this, death by strangulation, is not an ideal method of execution; and from the evidence that has accumulated it seems to me just to say that, short of decapitation, death by subaural knot is uncertain in its rapidity, and in its mocle of production.

Turning now to the second series, we have five sets of cervical vertebræ all showing an identical lesion-i.e., the fracture dislocation of the axis vertebra shown in Fig. 2. It

FIG. 2.

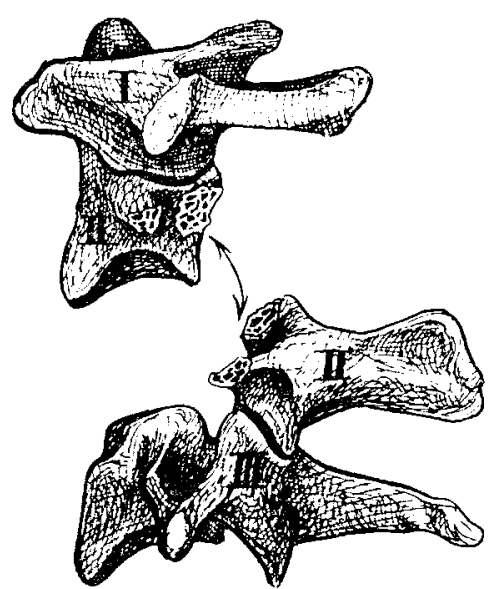

The lesion present in Captain C. F. Fraser's series of judicial hangings. Separation of the arch of the axis from the bods; effect of a submental knot.

is to be noted that the odontoid process plays no part in producing death, but that the posterior arch of the axis is snapped clean off and remains fixed to the third vertebra, while the atlas, the odontoid process, and the anterior arch of the axis remain fixed to the skull. This lesion is produced by the violent jerk which throws the man's head suddenly backwards and snaps his axis vertebra. Death in this series of cases was uniformly instantaneous, for the spinal cord was cleanly severed by the fracture of the neck. In every instance the knot was placed "a little to the left of the chin"-i.e., was a submental knot, or as near submental as the circumstances allowed. No more instructive illustration of the action of the submental knot could be furnished than that given in this series of Captain Fraser.

For a long while the facts here mentioned have been known in an indefinite way. The submental knot was strongly advocated to, and apparently approved by, the Committee on Capital Sentences in 1886, but it was not made a recommendation in its resolutions. It is used by medical officers upon whom the duty devolves in outlying stations, but it is not the English official judicial method. The reason for this, I think, is clear. Men were at one time hanged by the neck until they were dead-i.e., strangled; and at that time, as many old prints depict, the knot was suboccipital. With the introduction of the "drop" in 1818 this knot was found unsuitable, and a subaural knot was used. I imagine that these series of lesions will show clearly what many have advocated for years, that the submental knot should now supersede the subaural knot in our English judicial hangings.

A Centenarian.-According to the Westminster Gazette, Mrs. Ann Lacy, of Ramsgate, who celebrated the anniversary of her 100th birthday on Dec. 29th, has received a message of congratulation from the King. Except for deafness and failing sight, she enjoys good health. 